\title{
Manifestasi Good Governance Melalui Akuntabilitas Pengelolaan Dana Desa yang Didukung oleh Kompetensi Aparatur Pemerintah Desa
}

\author{
Agus Hakri Bokingo \\ Program Studi Manajemen, Fakultas Ekonomi Universitas Negeri Gorontalo \\ Email: agushakri@ung.ac.id
}

\begin{abstract}
The purpose of this research is to analyze the influence of village apparatus competency on the accountability of village fund management in order to realize good governance. This study involved 60 respondents who were officers in twelve different village offices in Boliyohuto Subdistrict in the Gorontalo District Government. The sample was taken using a proportional sampling technique in which each office recruited 5 respondents. The findings of the study showed that there was a significant effect of the competence of the village apparatus on the accountability of village fund management. These results indicate that in order to realize a government that is transparent, it must be supported by strengthening the competence of village officials.
\end{abstract}

Keywords: Accountability of Village Fund Management, Village Apparatus Competence

\begin{abstract}
Abstrak
Tujuan dilaksanakannya penelitian ini adalah untuk menganalisis pengaruh kompetensi aparatur desa terhadap akuntabilitas pengelolaan dana desa dalam rangka mewujudkan good governance. Penelitian ini melibatkan 60 orang responden yang merupakan aparat di dua belas kantor desa yang berbeda pada Kecamatan Boliyohuto di lingkungan Pemerintah Kabupaten Gorontalo. Sampel diambil menggunakan teknik proporsional sampling di mana tiap kantor direkrut sejumlah 5 orang responden. Temuan penelitian menunjukan bahwa terdapat pengaruh yang signifikan dari kompetensi aparatur desa terhadap akuntabilitas pengelolaan dana desa. Hasil ini mengindikasikan bahwa untuk mewujudkan pemerintahan yang transparansi, haruslah didukung oleh penguatan kompetensi aparatur desa.
\end{abstract}

Kata Kunci: Akuntabilitas Pengelolaan Dana Desa, Kompetensi Aparatur Desa

\section{I.PENDAHULUAN}

Sejak dirilisnya UU No. 6 Tahun 2014 tentang Desa, menjadikan desa memiliki wewenang dalam mengelola urusan pemerintahannya secara otonom. Begitupun dengan pelaksanaan pembangunan dalam rangka peningkatan kesejahteraan dan kualitas hidup masyarakat. Undang-undang tersebut mengamanatkan pemerintah desa agar mandiri dalam mengelola sumber daya termasuk keuangan desa. Sebab, pengalokasian dana desa menuntut tanggung jawab besar dari pemerintah. 
Demi mewujudkan tata kelola pemerintahan desa yang baik, maka pengelolaan keuangan desa mesti berasaskan pada prinsip akuntabilitas sebagai indikator good governace yang menjadi kunci penyelenggaraan pemerintahan desa yang bermuara pada pertanggungjawaban kepada masyarakat desa. Jumlah dana yang besar dan semakin membesar tiap tahunnya maka diperlukan pengelolaan keuangan desa yang akuntabel. Salah satu titik kritisnya adalah dalam proses pelaksanaan, penatausahaan dan pelaporan.

Pada Peraturan Bupati Nomor 41 Tahun 2009 tentang Pedoman Pelaksanaan Dana Desa secara implisit telah dijelaskan arah penggunaan dana desa agar berdasar pada skala prioritas tingkat desa yang merupakan hasil musrembangdes, sehingganya pendistribusian dana desa tidak dibagikan secara merata ke dusun/RW/RT. Pelaksanaan pengelolaan dana desa pun wajib dilaporkan oleh Tim Pelaksana Desa secara berjenjang kepada Tim Fasilitasi Tingkat Kecamatan dan Tim Fasilitasi Tingkat Kabupaten.

Berdasarkan data yang diperoleh dari Dinas Pemberdayaan Masyarakat Desa Kabupaten Gorontalo, besaran rincian sumber anggaran dana desa yang berada di Kabupaten Gorontalo tahun 2017 adalah sebesar Rp 244.414.441.900 yang akan dialokasikan kepada 191 desa di 18 kecamatan dalam komposisi proposional tiap desa yang terdiri dari Dana Desa, Alokasi Dana Desa, Bagi Hasil Retribusi Daerah, dan Bagi Hasil Pajak Daerah. Dengan pembagian tesebut diperoleh rincian sumber anggaran dana desa terendah adalah Desa Sidomulyo Kecamatan Boliyohuto dengan rincian Rp 1.035.437.900, sedangkan desa yang memperoleh rincian sumber anggaran tertinggi adalah Desa Daenaa Kecamatan Limboto Barat.

Kecamatan Boliyohuto sebagai salah satu kecamatan yang berada di Kabupaten Gorontalo yang sangat menarik untuk dilakukan penelitian tentang akuntabilitas pengelolaan dana desa yang teranggarkan di tahun 2017. Penelitian pengelolaan dana desa di Kecamatan Boliyohuto ini difokuskan pada penerapan prinsip akuntabilitas yang dilakukan Tim Pelaksana yang dibentuk di masing-masing desa. Prinsip akuntabilitas dalam pengelolaan dana desa diterapkan secara teratur mulai dari tahap perencanaan, pelaksanaan semua kegiatan, sampai setelah kegiatan, dengan tujuan agar pengelolaan dana desa dapat dipertanggung jawabkan. Berikut adalah tabel yang menyajikan pendistribusian sumber anggaran dana desa di wilayah Kecamatan Boliyohuto:

Tabel 1. Distribusi Anggaran Dana Desa Kecamatan Boliyohuto

\begin{tabular}{|c|l|c|}
\hline No & \multicolumn{1}{|c|}{ Desa } & Anggaran Dana Desa \\
\hline 1 & Sidomulyo & $\operatorname{Rp~} 1.035 .437 .900$ \\
\hline 2 & Parungi & $\operatorname{Rp~} 1.285 .591 .000$ \\
\hline 3 & Diloniyohu & $\operatorname{Rp~} 1.307 .895 .400$ \\
\hline 4 & Sidodadi & $\operatorname{Rp~} 1.112 .652 .000$ \\
\hline 5 & Potanga & $\operatorname{Rp~} 1.280 .641 .700$ \\
\hline 6 & Motoduto & $\operatorname{Rp~} 1.127 .620 .900$ \\
\hline
\end{tabular}




\begin{tabular}{|c|l|c|}
\hline 7 & Iloheluma & $\mathrm{Rp} 1.309 .344 .700$ \\
\hline 8 & Monggolito & $\mathrm{Rp} \mathrm{1.108.441.600}$ \\
\hline 9 & Bandung Rejo & $\mathrm{Rp} \mathrm{1.308.364.700}$ \\
\hline 10 & Dulohupa & $\mathrm{Rp} \mathrm{1.048.556.800}$ \\
\hline 11 & Sidomulyo Selatan & $\mathrm{Rp} \mathrm{1.051.337.700}$ \\
\hline 12 & Bongongoayu & $\mathrm{Rp} \mathrm{1.043.430.900}$ \\
\hline \multicolumn{2}{|c|}{ Jumlah } & $\mathrm{Rp} 14.019 .285 .300$ \\
\hline
\end{tabular}

Sumber:Bagian Pemerintah Desa, Desember 2017

Adanya dana desa yang menggunakan asas merata dan adil diharapkan setiap desa mampu melaksanakan pembangunan sesuai dengan rencana yang telah ditetapkan dalam musrembangdes. dalam mekanisme pengelolaan dana desa selanjutnya diserahkan kepada setiap desa dengan memperhatikan peraturan yang berlaku.

Berdasarkan Laporan Hasil Pemeriksaan Inspektorat Kabupaten Gorontalo atas pengelolaan keuangan desa terhadap 1 (satu) desa di wilayah Kecamatan Boliyohuto, khususnya untuk pengelolaan dana desa belum sepenuhnya sesuai dengan ketentuan yang ditetapkan. Penyelenggaraan administrasi keuangan di tingkat Desa secara umum belum terlaksanakan dengan baik dan benar. Kecamatan Boliyohuto dengan jumlah desa sebanyak 13 (Tiga belas) desa, terdapat 1 (satu) desa atau 1\% (satu perseratus) yang belum melaksanakan pertanggungjawaban dana desa sesuai dengan ketentuan tersebut.

Hasil Pemeriksaan Inspektorat terhadap pengelolaan keuangan desa di wilayah Kecamatan Boliyohuto, dapat dilihat dalam tabel 2. dibawah ini:

Tabel 2. Hasil Pemeriksaan Inspektorat terhadap pengelolaan keuangan desa di wilayah Kecamatan Boliyohuto

\begin{tabular}{|c|c|c|}
\hline No & Desa & Hasil Pemerisaan \\
\hline 1 & Sidomulyo & $\begin{array}{l}\text { a. SPJ sudah lengkap } \\
\text { b. Administrasi keuangan sudah dikerjakan secara } \\
\text { tertib dan benar }\end{array}$ \\
\hline 2 & Parungi & $\begin{array}{l}\text { a. SPJ sudah lengkap } \\
\text { b. Administrasi keuangan sudah dikerjakan secara } \\
\text { tertib dan benar }\end{array}$ \\
\hline 3 & Diloniyohu & $\begin{array}{l}\text { a. SPJ sudah lengkap } \\
\text { b. Administrasi keuangan sudah dikerjakan secara } \\
\text { tertib dan benar }\end{array}$ \\
\hline 4 & Sidodadi & $\begin{array}{l}\text { a. SPJ sudah lengkap } \\
\text { b. Administrasi keuangan sudah dikerjakan secara } \\
\text { tertib dan benar }\end{array}$ \\
\hline 5 & Potanga & a. SPJ sudah lengkap \\
\hline
\end{tabular}




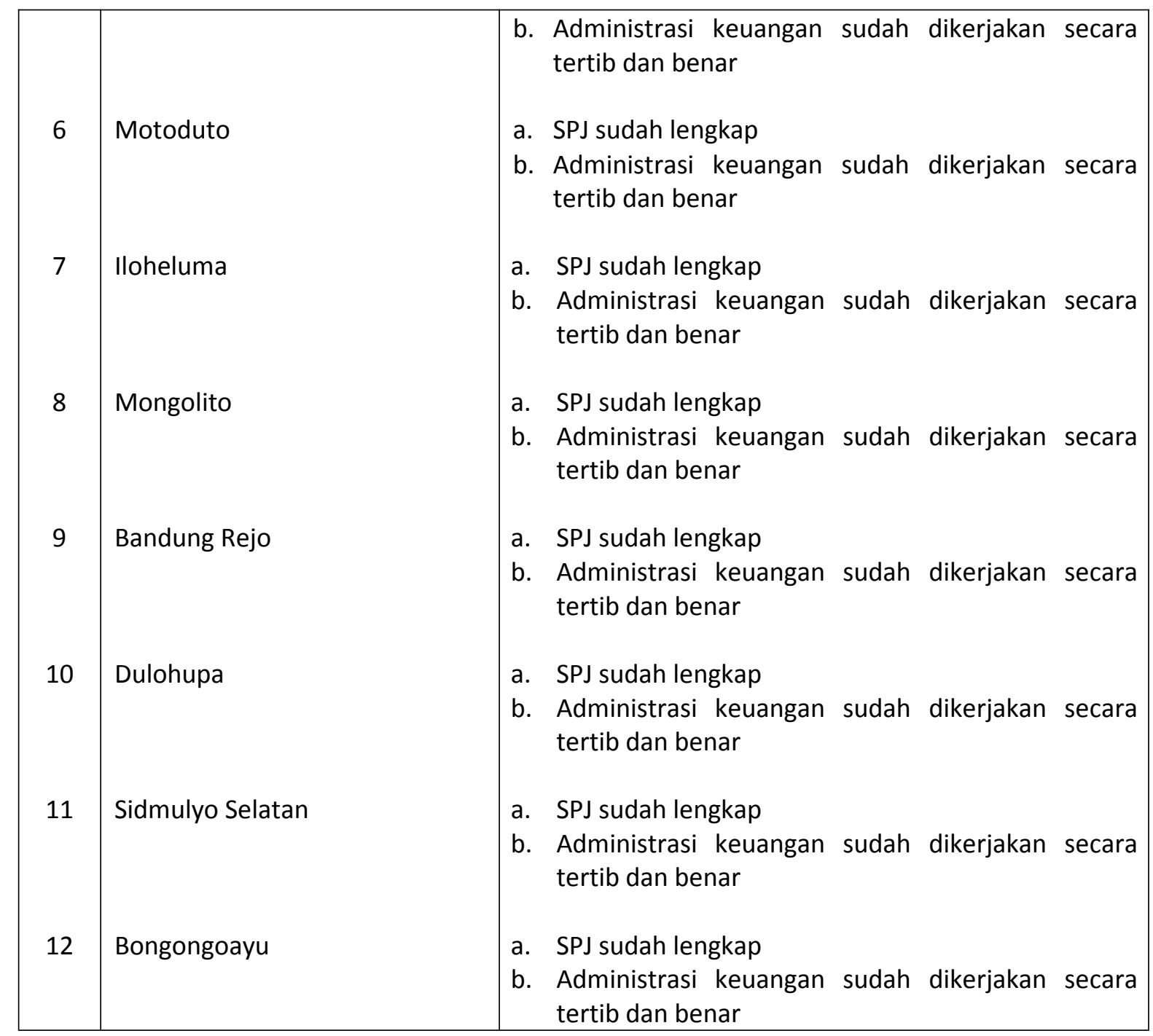

Sumber: Inspektorat Kabupaten Gorontalo 2018

Merujuk pada Perda Kabupaten Gorontalo Nomor 2 Tahun 2008 tentang Keuangan Desa, disebutkan bahwa dalam pelaksanaan Anggaran dan Belanja Desa (APBDesa) semua pengeluaran desa dilakukan melalui kas desa dan dibuktikan dengan bukti pengeluaran yang sah. Bendahara Desa juga wajib melakukan pembukuan atas seluruh transaksi baik penerimaan maupun pengeluaran Desa, dengan berpatokan pada sistem akuntansi pemerintahan (SAP). Ditinjau dari hal tersebut maka pertanggungjawaban pengelolaan keuangan desa di wilayah Kecamatan Boliyohuto belum sesuai dengan ketentuan yang berlaku (akuntabilitas pengelolan keuangan desa).

Selain itu, beberapa permasalahan lain yang terjadi antaranya: keterlambatan penyampaian laporan, belum berkesesuaian laporan pertanggungjawaban yang dibuat, penggunaan dana desa melewati batas 31 Desember tahun anggaran berkenaan, belum tertibnya administrasi keuangan, meningkatnya temuan desa, keterlambatan dalam 
penyusunan anggaran, dan belum optimalnya penyerapan anggaran, penggunaan dana desa diluar bidang prioritas, pengeluaran dana desa tidak didukung dengan bukti yang memadai, pekerjaan konstruksi dilakukan seluruhnya oleh pihak ketiga/ penyedia jasa, kelebihan pembayaran, pemungutan dan penyetoran pajak tidak sesuai, dana disimpan bukan di RKD, dan pengeluaran diluar APBDesa.

Menurut kajian peneliti dari berbagai sumber yang ada, sebagian besar alasan keterlambatan dalam hal pertanggungjawaban desa disebabkan oleh kemampuan sumber daya aparatur desa yang minim. Hal ini sebagian dijelaskan oleh Asri Juanita, Grace B Nangoi, Herman Karamoy (2016) bahwa, dalam pelaporan dan pertanggungjawab sudah dilaksnakan sesuai dengan mekanisme berdasarkan ketentuan walaupun masih terdapat kelalaian dari aparat desa dan mengelola teknis kegiatan.

Studi lain yang berkaitan dengan kompetensi aparatur desa yaitu Aditiya Nugroho Jati (2016) menyatakan dalam hasil penelitiannya mengenai Kompetensi Aparatur Desa Dalam Menghadapi Undang-undang No 6 Tahun 2014 menunjukkan bahwa untuk Kompetensi Aparatur Desa di Desa Toapaya Selatan dalam pengalokasian dana desa telah tepat sasaran, namun untuk pemerataan pembangunan di Desa Toapayabelum berjalan dengan maksimal. Hal ini disebabkan karena keterbatasan anggaran yang dikuncurkan oleh pemerintah pusat.

\section{METODE}

Penelitian ini menggunakan metode kuantitatif dengan basis atau sumber data primer yang diperoleh langsung dari 60 orang responden yang merupakan aparatur dari 12 kantor desa pada Kecamatan Boliyohuto Kabupaten Gorontalo melalui angket penelitian. Data yang diperoleh diolah dan dianalisis dengan menggunakan teknik analisis regresi sederhana.

\section{HASIL DAN PEMBAHASAN}

\section{A. Hasil Analisis Regresi Sederhana}

Analisis regresi linier sederhana adalah analisis untuk mengetahui hubungan secara linear antara satu variabel independen $(X)$ dengan variabel dependen $(\mathrm{Y})$. Analisis ini berguna untuk mengetahui arah hubungan antara variabel independen dengan variabel dependen apakah positif atau negatif dan untuk memprediksi nilai dari variabel dependen apabila nilai variabel independen mengalami kenaikan atau penurunan. Analisis regresi pada penelitian ini dijelaskan pada tabel berikut: 
Tabel 3. Hasil Analisis Regresi Sederhana

\begin{tabular}{|l|c|c|c|c|c|}
\hline \multirow{2}{*}{ Model } & \multicolumn{2}{|c|}{$\begin{array}{c}\text { Unstandardized } \\
\text { Coefficients }\end{array}$} & $\begin{array}{c}\text { Standardized } \\
\text { Coefficients }\end{array}$ & t & Sig. \\
\cline { 2 - 4 } & $\mathrm{B}$ & Std. Error & Beta & & \\
\hline $\begin{array}{l}\text { (Constant) } \\
\begin{array}{l}\text { Kompetensi Aparatur } \\
\text { Desa }\end{array}\end{array}$ & 85,622 & 9,762 & & 8,771 &, 000 \\
\hline
\end{tabular}

a. Dependent Variable: $Y$

Sumber: Data olahan SPSS 21, 2018

Berdasarkan analisis regresi pada tampilan output SPSS tabel diatas, maka diketahui persamaan regresinya: $\hat{Y}=85,622+0,420$ Dari persamaan regresi yang diperoleh, dapat dijelaskan bahwa:

1. Nilai Konstan: 85,622

Nilai konstan (konstanta) berlaku untuk variabel Y yakni Akuntabilitas pengelolaan dana desa di Kecamatan Boliyohuto, nilai konstan tersebut menjelaskan bahwa apabila seluruh model dalam penelitian atau variabel $X$ yakni Kompetensi Aparatur Desa di Kecamatan Boliyohuto tidak memiliki pengaruh terhadap variabel terikat, maka nilai aku saat ini adalah akuntabilitas pengelolaan dana desa sebesar 85,622 poin.

2. Nilai Regresi variabel Kompetensi: 0,420

Nilai regresi variabel $X$ yakni kompetensi aparatur desa sebesar 0,420 poin, yang menjelaskan bahwa jika kompetensi aparatur desa yang ditawarkan di Kecamatan Boliyohuto mengalami kenaikan 1 point/satuan maka hal tersebut akan meningkatkan nilai kompetensi aparatur desa sebesar 0,827 poin.

\section{B. Pengujian Hipotesis}

Uji t berguna untuk menguji variabel bebas terhadap variabel terikatnya. Setelah dianalisis secara regresi, maka selanjutnya dilakukan pengujian lebih lanjut untuk mengetahui koefisien regresi variabel secara lebih spesifik yang bertujuan untuk mengetahui pengaruh dari variabel bebas terhadap variabel terikatnya. Adapun tahapan pengujian yang akan dilakukan adalah sebagai berikut:

$\mathrm{HO}: \beta \leq 0$ maka variabel bebas tidak berpengaruh terhadap variabel terikat.

$\mathrm{H} 1: \beta>0$ maka variabel bebas berpengaruh terhadap variabel terikat.

Hipotesis diterima dengan ketentuan sebagai berikut:

a. Jika $t_{\text {hitung }}<\mathrm{t}_{\text {tabel }}$ maka $\mathrm{HO}$ diterima dan $\mathrm{H} 1$ dotolak

b. Jika $t_{\text {hutung }}>t_{\text {tabel }}$ maka $\mathrm{H} 1$ diterima dan $\mathrm{HO}$ ditolak

Selain itu uji t tersebut dapat pula dilihat dari besarnya probabilitas value ( $\mathrm{p}$ value) dibandingkan dengan 0,05 (tarif signifikansi $a=5 \%$ ). Adapun kriteria pengujian yang digunakan adalah: Jika $p_{\text {value }}<0,05$ maka $\mathrm{HO}$ ditolak, jika $p_{\text {value }}>0,05$ maka HO diterima. 
Sebelum melakukan pengujian koifisien regresi melalui uji $\mathrm{t}$ (parsial), maka terlebih dahulu perlu mencari nilai $t$ tabel. Pencarian nilai $t$ tabel bergantung pada besarnya df (degree of freedom) serta tingkat signifikansi yang digunakan. Dengan menggunakan tingkat signifikansi sebesar $5 \%$ dan nilai df sebesar n-k-1 ( $n$ adalah jumlah kasus dan $\mathrm{k}$ adalah jumlah variabel independen), sehingga 60 diperoleh nilai t-tabel sebesar 1,671. Berdasarkan acuan tersebut, maka dilakukan pengujian berdasarkan nilai $t$ hitung variabel bebas terhadap nilai t tabelnya.

Tabel 4. Perbandingan Nilai $t_{\text {hitung }}$ dan $t_{\text {tabel }}$

\begin{tabular}{|c|c|c|c|}
\hline $\mathrm{df}$ & $\mathrm{t}_{\text {hitung }}$ & $\mathrm{t}_{\text {tabel }}$ & Sig \\
\hline 60 & 3.529 & 1.671 & 0.001 \\
\hline
\end{tabular}

Sumber: Data diolah

Berdasarkan tampilan output SPSS pada tabel 20. diperoleh nilai t-hitung untuk variabel Kompetensi Aparatur Desa di Kecamatan Boliyohuto sebesar 3,529 dengan nilai signifikansi sebesar 0,001. Sebelumnya bahwa telah diketahui nilai t tabel sebesar 1,671 yang apabila nilai keduanya dibandingkan maka nilai t hitung lebih besar dari nilai $t$ tabel. Adapun berdasarkan nilai signifikansinya $(0,001)$ masih jauh lebih kecil dari nilai alpha $(0,05)$. Hal tersebut juga didukung oleh nilai koefisien regersi sebesar 0,420 atau lebih besar dari skala 0,05.

Berdasarkan penjelasan diatas, maka dapat disimpulkan bahwa hipotesis yang disusun sebelumnya terbukti atau diterima ( $\mathrm{H} 1$ diterima dan HO ditolak), yang menjelaskan bahwa kompetensi aparatur desa memiliki pengaruh yang signifikan terhadap akuntabilitas pengelolaan dana desa di Desa Motoduto Kecamatan Boliyohuto.

\section{Koefisien Determinasi}

Untuk mengetahui besar pengaruh dari variabel bebas dalam model terhadap variabel terikatnya, digunakan analisis koeifsien determinasi. Nilai koefisien determinasi mencerminkan besarnya pengaruh perubahan variabel bebas dalam menjalankan perubahan pada variabel tidak bebas secara bersama-sama. Besarnya nilai $\mathrm{R}^{2}$ berkisar antara $0<R^{2}<1$.Jika nilai $R^{2}$ semakin mendekati satu maka model yang diusulkan dikatakan baik karena semakin tinggi variasi variabel dependen yang dapat dijelaskan oleh variabel independen. Adapun nilai determinasi dapat diketahui pada tabel berikut:

Tabel 5. Koefisien Determinasi

\begin{tabular}{|c|c|c|c|c|}
\hline \multicolumn{5}{|c|}{ Model Summary $^{\mathrm{b}}$} \\
\hline Model & $\mathrm{R}$ & $\mathrm{R}$ Square & $\begin{array}{c}\text { Adjusted } \mathrm{R} \\
\text { Square }\end{array}$ & $\begin{array}{c}\text { Std. Error of the } \\
\text { Estimate }\end{array}$ \\
\hline 1 &, $420^{\mathrm{a}}$ &, 540 &, 163 & 5,73846 \\
\hline \multicolumn{5}{|c|}{ a. Predictors: (Constant), $\mathrm{X}$} \\
\hline
\end{tabular}

Sumber: Data Olahan SPSS 21, 2018

http://jurnal.stiekma.ac.id/index.php/JAMIN 
Berdasarkan tampilan output SPSS diatas, diketauhi bahwa nilai $R$ sebesar 0,420 dan nilai $R$ square $\left(R^{2}\right)$ sebesar $\mathbf{0 , 5 4 0}$. Hal tersebut menjelaskan bahwa sebesar $54 \%$ dari variabel bebas (Kompetensi aparatur desa) memiliki kontribusi untuk mempengaruhi akuntabilitas pengelolaan dana desa di Kecamatan Boliyohuto. Adapun sisanya sebesar $46 \%$ memungkinkan untuk dipengaruhi oleh faktor-faktor (variabel) lainnya yang tidak dijelaskan pada penelitian ini seperti motif, karakteristik serta konsep diri.

\section{Pembahasan}

Besarnya koefisien determinasi atau angka $R$ Square adalah sebesar 0,540 . Hal tersebut menjelaskan bahwa sebesar $54 \%$ dari variabel bebas (Kompetensi aparatur desa) memiliki kontribusi untuk mempengaruhi akuntabilitas pengelolaan dana desa di Kecamatan Boliyohuto. Adapun sisanya sebesar $46 \%$ memungkinkan untuk dipengaruhi oleh faktor-faktor (variabel) lainnya yang tidak dijelaskan pada penelitian ini seperti motif, karakteristik serta konsep diri.

Menurut pembuktian hipotesis menunjukan bahwa hipotesis diterima. Artinya bahwa kompetensi aparatur desa memiliki pengaruh yang signifikan terhadap akuntabilitas pengelolaan dana desa di Desa Motoduto Kecamatan Boliyohuto. Dari distribusi jawaban responden yang diterima, maka diperoleh sebesar $145 \%$ dan $153 \%$ dari seluruh jawaban yang diterima. Artinya bahwa jawaban yang diberikan termasuk pada kategori yang baik yang artinya responden (aparat) desa memiliki penilaian kerja yang baik.

Hasil signifikan karena kompetensi aparatur desa akan memberikan dampak yang kuat bagi akuntanbilitas pengelolaan dana desa. Akuntabilitas pengelolaan dana desa yang berkualitas merupakan akuntabilitas pengelolaan dana desa yang memenuhi 5 aspek penting yakni perencanaan, pelaksanaan, penatausahaan, pelaporan dan pertanggungjawaban. Sebagaimana hasil pengujian deskriptif ditemukan bahwa skor capain untuk variabel Akuntabilitas Pengelolaan Dana Desa adalah 153\% yang berada pada kategori yang baik. Hal ini menunjukan bahwa pemerintah desa di Kecamatan Boliyohuto Kabupaten Gorontalo mampu mencapai hasil akuntabilitas pengelolaan dana desa yang baik sehingga sehingga mampu menghasilkan akuntabilitas pengelolaan dana desa yang berkualitas.

Kemudian dari tabel di atas juga terlihat bahwa indikator yang terbesar indikator yang ke tiga dan ke empat yakni sebesar $156 \%$ mengenai penatausahaan dan pelaporan. Sementara skor terendah yakni pada indikator kedua $150 \%$ yakni mengenai pelaksanaan pengelolaan dana desa.

Perencanaan dan pertanggungjawaban merupakan akuntabilitas yang menjadi sebuah bahan pertimbangan dalam pengambilan keputusan. Hasil pengujian deskriptif menemukan bahwa indikator perencanaan dan pertanggungjawaban terletak pada kriteria yang sangat baik dengan skor sebesar $152 \%$. Dalam penyusunan akuntabilitas pengelolaan dana desa sebaiknya akuntabilitas pengelolaan dana desa tersebut dapat menatausaha denga baik. Indikator ini terletak pada kriteria yang sangat dengan skor sebesar $156 \%$.

Indikator yang menyangkut pelaporan dari angka-angka dalam akuntabilitas pengelolaan dana desa ini terletak pada kriteria yang sangat baik dengan skor sebesar 
156\%. Hal ini menunjukan bahwa pelaporan akuntabilitas pengelolaan dana desa di Kecamatan Boliyohuto Kabupaten Gorontalo dapat di terima.

Kompetensi aparatur desa menjadi sangatlah penting bagi aparatur. Kompetensi aparatur desa yang benar dan pemahaman yang baik terhadap akuntabilitas pengelolaan dana desa oleh pengelolola keuangan Satuan Kerja Perangkat Desa (SKPD) tentunya akan meningkatkan akuntabilitas pengelolaan dana desa. Hal tersebut sebagaimana pengujian deskriptif ditemukan bahwa skor capaian untuk variabel kompetensi aparatur desa adalah sebesar $145 \%$ yang berada pada kategori yang baik. Hal ini menunjukan bahwa aparutur Kecamatan Boliyohuto Kabupaten Gorontalo telah mampu untuk menerapkan kompetensi aparautur desa yang ditandai dengan baiknya atau tungkat kewajaran yang baik dari akuntabilitas pengelolaan dana desa di Kecamatan Boliyohuto Kabupaten Gorontalo. Kemudian dari tabel di atas juga terlihat bahwa indikator yang terbesar yakni indikator satu dan tiga yakni mengenai pengetahuan dan sikap kerja. Sementara itu indikator yang terendah yakni indikator kedua mengenai keterampilan.

Melalui hasil ini maka sangat diperlukan langkah kongkrit dari aparatur yakni dengan terus meningkatkan faktor-faktor penting yang dapat membuat akuntabilitas pengelolaan dana desa. Langkah yang perlu dilakukan yakni dengan mempererat komunikasi dan koordinasi antar kepala desa di lingkungan Kecamatan Boliyohuto Kabupaten Gorontalo. Kemudian meningkatkan kinerjanya dengan cara mengikuti pelatihan dan bimbingan. bimbingan dan pelatihan pada dasarnya akan menambah wawasan dari pihak aparatur desa Kecamatan Boliyohuto Kabupaten Gorontalo dalam mengembangkan kompetensinya terkait dengan cara untuk memahami setia aturan yang ada termasuk Permendagri No. 113 Tahun 2014 dan Undang-Undang Desa Nomor 6 Tahun 2014 mengenai mengenai pengelolaan dana desa.

\section{SIMPULAN}

Berdasarkan hasil penelitian dan pembahasan diatas, maka dapat ditarik kesimpulan bahwa pengaruh signifikan Dari Kompetensi Aparatur Desa terhadap Akuntabilitas Pengelolaan Dana Desa di Kecamatan Boliyohuto Kabupaten Gorontalo besarnya koefisien determinasi atau angka $R$ Square adalah sebesar 0,540. Nilai ini menunjukan bahwa sebesar 54\% variabilitas Akuntabilitas Pengelolaan Dana Desa di Kecamatan Boliyohuto Kabupaten Gorontalo dapat dipengaruhi oleh Kompetensi Aparatur Desa, sedangkan sisanya sebesar $46 \%$ dipengaruhi oleh variabel lain yang tidak diteliti dalam penelitian ini.

\section{SARAN}

Berdasarkan hasil penelitian yang telah dilakukan maka beberapa saran yang dapat disampaikan untuk penelitian yang akan datang adalah sebagai berikut:

1. Bagi aparat desa yang ada di Kecamatan Boliyohuto penelitian ini diharapkan dapat dijadikan sebagai masukan dalam meningkatkan kerja aparat desa dalam akuntabilitas pengelolaan dana desa. Aparat desa harus lebih meningkatkan pengetahuannya dalam hal pengelolaan dana desa khususnya mengenai perencanaan, penggunaan, penatausahaan, pelaporan dan pertanggungjawaban. 
2. Bagi penelitian selanjutnya, diharapkan dapat memperluas lokasi penelitian dibeberapa tempat dan menambah variabel penelitian yang akan diteliti sehingga dapat membandingkan dengan hasil pengujian yang ditemukan sebelumnya.

3. Kiranya penelitian ini dapat dijadikan acuan/ referensi bagi pihak lain untuk dapat menambah faktor atau variabel lainnya, serta mengubah objek penelitian.

\section{DAFTAR PUSTAKA}

Abdul, M. 2014. Manajemen dan Evaluasi Kinerja Karyawan.Yogyakarta: Aswaja pressindo..

Aprinto, SPHR. Brian dan Fonny Arisandy Jacob. 2013. Pedoman Lengkap Profesional SDM Indonesia. PPM: Jakarta

Baron, Angela dan Michael Amstrong. 2013. Human Capital Management. Terjemahan Lilian Juwono, Jakarta: PPM.

Halim, Abdul dan Muhammad Iqbal 2012. Pengelolaan Keuangan Daerah. UPP STIM YKPN. Yogyakarta.

Kumolo, Tjahjo. dkk. 2017. Nawa Cita Untuk Kesejahteraan Rakyat Indonesia (integritas perencanaan pembangunan nasional dan daerah). Jakarta: PT Kompas Media Nusantara.

Lapananda, Y. 2016. Hukum Pengelolaan Keuangan Desa. Jakarta : PT. Wahana Semesta Intermedia.

Mahmudi. 2011. Akuntansi Sektor Publik. Yogyakarta: UII Pres

Subroto, Agus. 2013. Akuntansi Pengelolaan Dana Desa. Tesis S-2 Program Pasca Sarjana Universitas Diponegoro Semarang.

Sugiyono. 2013. Metode Penelitian Kuantitatif, Kualitatif dan R\&D. Cetakan Ke-19. Bandung: CV. Alfabeta.

Sujarweni, V. Wiratna. 2015. Akuntansi Sektor Publik: Teori, Konsep, dan Aplikasi. Yogyakarta: Pustaka Baru.

Sumodiningrat, Gunawa; dan Ari Wulandari. 2016. Membangun Indinesia Dari Desa. Cetakan ke-1. Yogyakarta: Media Perindo.

Sutrisno, Edy. 2014. Manajemen Sumber Daya Manusia. Cetakan Ke-6. Jakarta: Kencana Prenada Media Group.

Tahir, Arifin. 2011. Kebijakan Transparansi Penyelenggaraan Pemerintah Daerah. Pustaka Indonesia Press. Jakarta.

Peraturan Kepala Badan Kepegawaian Negara Nomor 8 Tahun @013 Tentang Perumusan Standar Kompetensi Teknis Pegawai Negeri Sipil.

Peraturan Pemerintah 6 Tahun 2014 Tentang Desa (c.72) Jakarta, Pemerintahan Negara Kesatuan Republik Indonesia.

Peraturan Menteri Dalam Negeri No 113 tahun 2014 tentang Pedoman Pengelolaan Keuangan Desa. 